\title{
Fusion of a cervical sympathetic ganglion with the recurrent inferior laryngeal nerve: a case of false positive non-recurrent inferior laryngeal nerve
}

\author{
Fahri Yetișir', A. Ebru Salman², Alper Bilal Özkardeș, Seyit Murat Aydın¹, Mehmet Kılıç
}

An anastomosis between the recurrent inferior laryngeal nerve (RILN) and the cervical sympathetic ganglion is seen rarely and might be confused with non-recurrent inferior laryngeal nerve (NRILN) in patients undergoing thyroidectomy and parathyroidectomy. In spite of the fact that NRILN is rarely seen and is an important anatomical structure, when damaged, the quality of life of the patient is negatively affected. This case report describes a connection between the RILN and the sympathetic nerve ganglion encountered during nerve dissection in a 43 year old female patient undergoing thyroidectomy and central zone dissection. Key points in the differential diagnosis are discussed.

Key Words: Sympathetic nerve, recurrent laryngeal nerve, thyroid, non-recurrent laryngeal nerve

'Ministry of Health Ankara Atatürk Teaching Hospital, Department of General Surgery, Ankara, Turkey

${ }^{2}$ Ministry of Health Ankara Atatürk Teaching Hospital, Department of Anesthesia and Reanimation, Ankara, Turkey

\section{Address for Correspondence} Dr. Fahri Yetişir

Ministry of Health Ankara Atatürk Teaching Hospital, Department of General Surgery, Ankara, Turkey

Phone: +90312 2198062 e-mail:drfahriyetisir@hotmail.com

Received: 16.01 .2012

Accepted: 27.02.2012

Online Available Date: 28.05.2013

OCopyright 2013 by Turkish Surgical Association

Available online at www.ulusalcerrahidergisi.org

\section{INTRODUCTION}

The most important step during thyroidectomy, parathyroidectomy and neck surgeries involving the $6^{\text {th }}$ level is the dissection and preservation of RILN. The variability in the trajectory of this nerve and its rare fusion with other nerves can make the dissection difficult and it can be mistaken for different nerves. Injury to RILN results in serious complications like hoarseness and respiratory distress. Minimizing the risk of injury to the nerve in patients undergoing thyroid and parathyroid surgery is essential for the quality of life. The fusion of sympathetic nerve with RILN (false NRILN) and NRILN are rare abnormalities, which can be confused with each other (1).

This case report emphasizes the properties that differentiate the fusion of sympathetic nerve with RILN and NRILN.

\section{CASE PRESENTATION}

A forty-three year old female presented with a lump in her neck. She had noticed mass a long time ago however it started to grow lately. On her physical examination bilateral, multiple nodules were palpated in the thyroid gland. The thyroid ultrasound showed multiple nodules reaching up to the size of $3 \times 2 \mathrm{~cm}$ in the right lobe and $2 \times 2 \mathrm{~cm}$ in the left lobe. The sintigraphy revealed that the large nodule on the right side was a cold nodule and a fine needle aspiration biopsy was taken. The result was suspicious. Operation was planned together with frozen section evaluation. During the operation after the inferior thyroid artery was hanged with a vessel loop, the right recurrent laryngeal nerve was dissected and it was seen that it unites with another nerve. Keeping in mind that this nerve might be a non recurrent laryngeal nerve, the pulse of the aberrant subclavian artery (arteria lusoria) was searched behind the oesophagus but was not found. The dissection was carried out in the lateral direction. Upon completion of the dissection it was clear that this nerve was not a NRLN, by seeing the nerve ganglion and the thickening-thining of the nerve. It was found out that this nerve was the sympathetic ganglion and that it fuses with RILN (Figure 1). The frozen section evaluation revealed papillary carcinoma. A total thyroidectomy and central zone dissection was done after dissection of the left RILN, with preservation of the parathyroid glands. Vocal cords were mobile in indirect laryngoscopy and the patient did not experience any complications. The right common carotid artery was visualized in the neck with a postoperative $3.5 \mathrm{MHz}$ ultrasound (Mindray-D8). It was observed that the artery unites with the right subclavian artery forming a $Y$ shaped brachiocephalic artery before entering the aortic arch (Figure 2). The finding that there was no abnormality of the right subclavian artery(arteria lusoria) confirmed that the nerve was not a right NRILN (2). The sympathetic nerve seen in this case carries nearly all of the properties of a false NRILN listed in the table, although it was very thick (Table 1). 

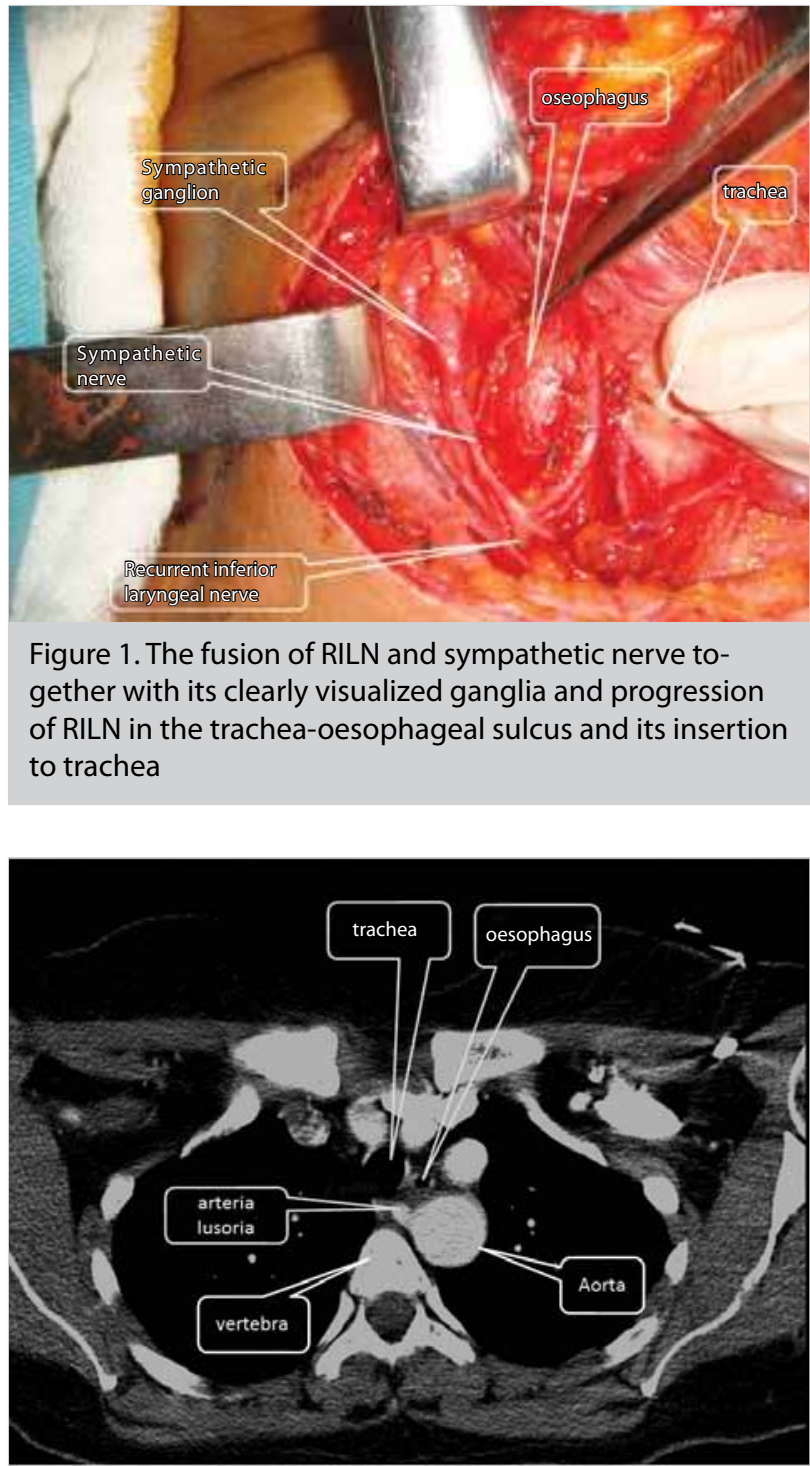

Figure 3. The trajectory of the right subclavian artery anomaly (arteria lusoria) accompanying NRILN in the posterior of the oesophagus and trachea

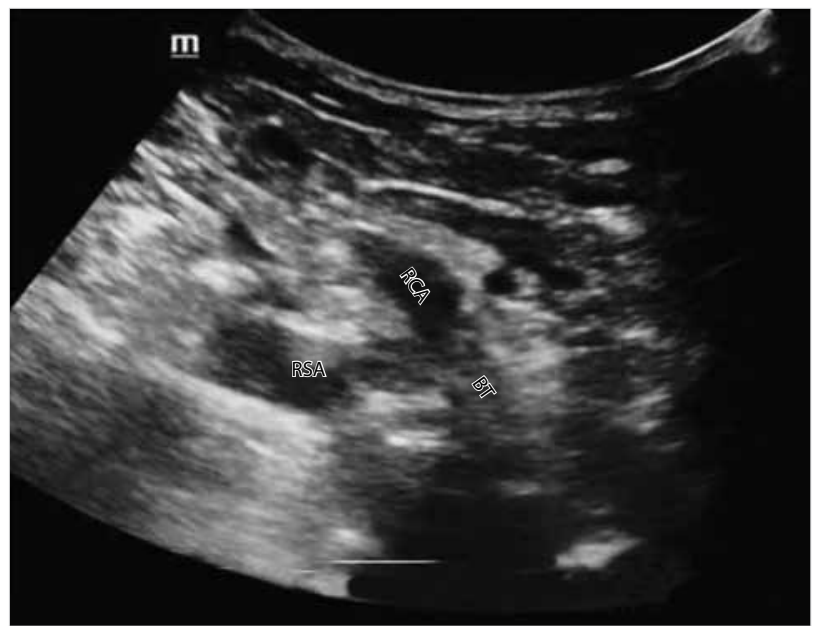

Figure 2. The right carotid artery combines with right subclavian artery forming the brachiocephalic trunk to reach the aortic arch. Ultrasonography clearly depicts the $Y$ sign

\section{DISCUSSION}

An anastomosis between the recurrent inferior laryngeal nerve (RILN) and the sympathetic ganglion might be mistaken for a non-recurrent inferior laryngeal nerve (NRILN) in patients undergoing thyroidectomy, parathyroidectomy or neck surgeries involving the $6^{\text {th }}$ level.

Nonrecurrent inferior laryngeal nerve is a rare anatomic variation that should be taken into consideration during thyroidectomy or parathyroidectomy to prevent nerve injury (3). It is usually seen in the right. The incidence is $0.3-1.6 \%$ (4). Due to embryologic development abnormality of the aortic arch, direct origin of the carotid artery from the posterior aspect of aorta, the absence of brachiocephalic artery and presence of aberrant subclavian artery (arteria lusoria) are also diagnostic. NRILN can be recognized preoperatively by identification of the previously mentioned vascular abnormalities or during nerve dissection. Tomography is effective in showing the aberrant subclavian artery (arteria lusoria) during its co-

Table 1. Key points in differentiating NRILN from sympathetic nerve and RILN fusion

\begin{tabular}{lll} 
& NRILN & Sympathetic nerve and RILN fusion \\
\hline Pulsation behind oesophagus & + & - \\
Y sign & - & + \\
\hline Aberrant right subclavian artery (arteria lusoria) & + & - \\
\hline Fusiform structure of the nerve (ganglion structure) & - & + \\
Branching to adjacent tissue and other nerves & rare & more frequent \\
\hline Thinning and thickening of the nerve & rarley seen & usually present \\
Originating from vagus & + & - \\
\hline Nerve thickness & usually equal to RILN width & usually thinner, very \\
& & rarely thick \\
Nerve trajectory & usually horizontal & any direction \\
Nerve direction & towards carotid sheath & towards the posterior of the carotid sheath \\
$\begin{array}{l}\text { Complications in case of injury to } \\
\text { the nerve }\end{array}$ & hoarseness and respiratory distress & sympathetic nerve injury effects
\end{tabular}


urse from the posterior of the membranous wall of trachea (Figure 3$)(2,5,6)$. On ultrasonography, visualization of bifurcation of the brachiocephalic trunk into common carotid artery and right subclavian artery ( $\mathrm{Y}$ sign) indicates presence of RILN (7). Cervical 3.5 MHz ultrasonography was shown to be $100 \%$ predictive for the presence of right NRILN in a study done on 2330 thyroidectomy patients $(8,9)$. In this case we have seen the $\mathrm{Y}$ sign with $3.5 \mathrm{MHz}$ ultrasonography, therefore proving this nerve not to be a true NRILN.

It is known that communicating branches exist between the cervical sympathetic system and RILN (10). These communicating branches usually arise from the middle sympathetic ganglion, less frequently from the superior cervical ganglion or directly from the sympathetic trunk. Table 1 summarizes points to differentiate sympathetic nerve and NRILN. If the sympathetic nerve-RILN anastomosis is as large as RILN it can be mistaken for a NRILN. Recognition of this anatomic variation during cervical dissection might avoid injury to RILN in its normal course. When a structure coursing transversely between the carotid sheath and thyroid is seen, it should be dissected and found out if it originates from the sympathetic ganglion or the vagal nerve (11).

Another structure that can also be confused for NRILN during level VI dissection is the Galen nerve (12). This anastomosis between the RILN and external branch of superior laryngeal nerve courses vertical when compared to NRILN.

\section{CONCLUSION}

Knowledge of the anatomy of the recurrent inferior laryngeal nerve and anatomic structures that can be mistaken for RILN and NRILN is essential to perform a safe surgery.

Conflict of Interest: No conflict of interest was declared by the authors.

Peer-review: Externally peer-reviewed.
Author Contributions: Study concept and design - F.Y., A.E.S.; Acquisition of data - F.Y., A.B.Ö., S.M.A., M.K.; Analysis and interpretation of data - F.Y., A.E.S., M.K.; Preparation of the manuscript - F.Y., A.E.S.

\section{REFERENCES}

1. Raffaelli $M$, lacobone $M$, Henry JF. The 'false 'nonrecurrent inferior laryngeal nerve. Surgery 2000; 128: 1082-1087. [CrossRef]

2. Yetisir F, Salman AE, Çiftçi B, Teber A, Kiliç M. Efficacy of ultrasonography in identification of non-recurrent laryngeal nerve. Int J Surg 2012; 10: 506-509. [CrossRef]

3. Brauckhoff M, Walls G, Brauckoff K, Thanh PN, Thomusch O, Dralle $\mathrm{H}$. Identification of the nonrecurrent inferior laryngeal nerve using intraoperative neurostimulation. Langenbeck's Arch Surg 2002; 386: 482-487. [CrossRef]

4. Toniato A, Mazzarotto R, Piotto A, Bernante P, Pagetta C, Pelizzo MR. Identification of the nonrecurrent laryngeal nerve during thyroid surgery: 20-year experience. World J Surg 2004; 28: 659661. [CrossRef]

5. Wang Y, Ji Q, Li D, Wu Y, Zhu Y, Huang C, et al. Preoperative CT diagnosis of right nonrecurrent inferior laryngeal nerve. Head Neck 2011; 33: 232-238. [CrossRef]

6. Lee YS, Son EJ, Chang HS, Chung WY, Nam KH, Park CS. Computed tomography is useful for preoperative identification of nonrecurrent laryngeal nerve in thyroid cancer patients. Otolaryngol Head Neck Surg 2011; 145: 204-207. [CrossRef]

7. lacobone M, Viel G, Zanella S, Bottussi M, Frego M, Favia G. The usefulness of preoperative ultrasonographic identification of nonrecurrent inferior laryngeal nerve in neck surgery. Langenbecks Arch Surg 2008; 393: 633-638. [CrossRef]

8. Yusuf T, Levy MJ, Wiersema MJ, Clain JE, Harewood GC, Rajan E, et al. Utility of endoscopic ultrasound in the diagnosis of aberrant right subclavian artery. J Gastroenterol Hepatol 2007; 22: 1717-1721. [CrossRef]

9. Huang SM, Wu TJ. Neck ultrasound for prediction of right nonrecurrent laryngeal nerve. Head Neck 2010; 32: 844-849.

10. Steinberg JL, Khane GJ, Fernandes CM, Nel JP. Anatomy of the recurrent laryngeal nerve: a redescription. J Laryngol Otol 1986; 100: 919-927. [CrossRef]

11. Kocatürk S, Yıldırım A, Kunt T. Kocatürk S, Yıldırım A, Kunt T. The nonrecurrent nerve in thyroidectomy and its importance: A Case Report. KBB-Forum 2004; 3: 89-91.

12. Thompson NW. In discussion of Henry et al. Surgery 1998; 104: 977-984. 